\title{
Erratum to: Cellulose acetate from biomass waste of olive industry
}

Othman A. Hamed • Shehdeh Jodeh •

Nisreen Al-Hajj · Emad M. Hamed •

Ahmed Abo-Obeid · Yusra Fouad

Published online: 3 April 2015

(C) The Japan Wood Research Society 2015

\section{Erratum to: J Wood Sci (2015) 61:45-52}

DOI 10.1007/s10086-014-1442-y

After publication of the paper, some errors were found in the abstract, Figs. 3 and 5. In the original paper published, the following changes should be made. The changes do not affect the conclusions of the paper.

- In the 5th line of abstract section, the letter "p" should be omitted in the phrase "and multistep bleaching $p$ sequences".

- Figures 3 and 5 should be replaced with the following figures.

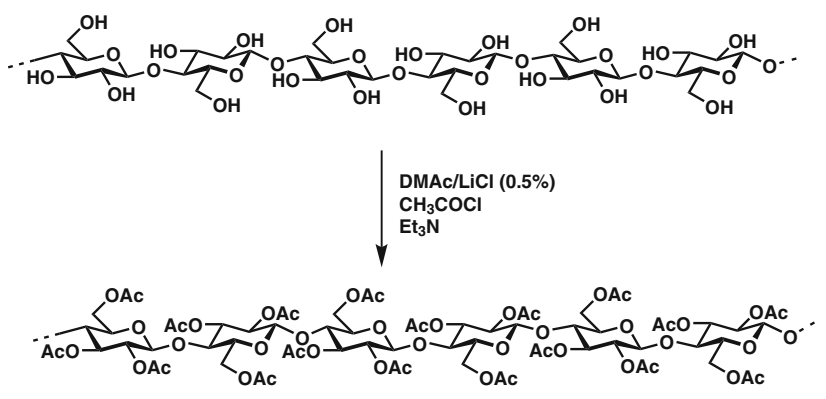

Fig. 3 A representative reaction diagram for converting cellulose powder into CTA

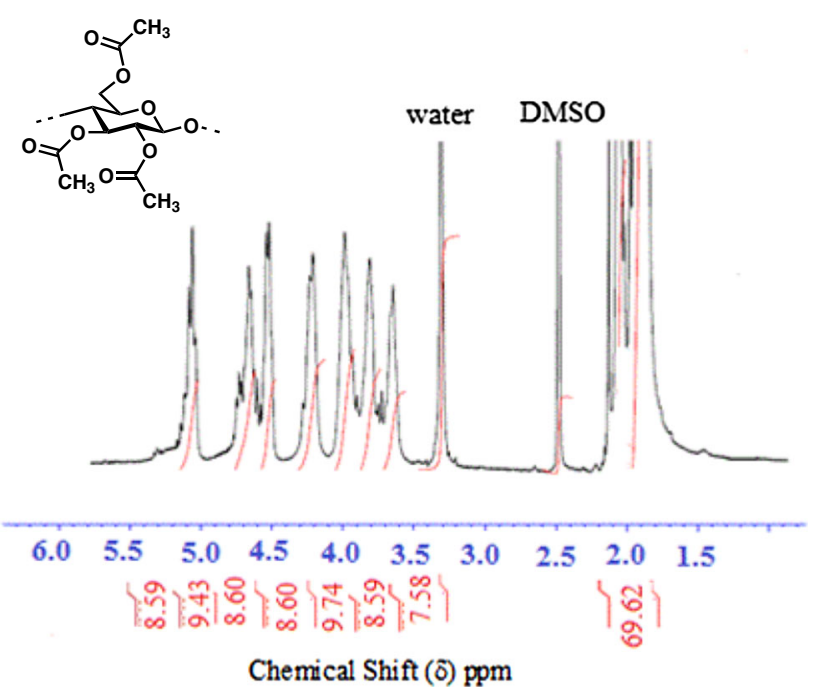

Fig. $5{ }^{1} \mathrm{H}$ NMR of cellulose triacetate prepared from cellulose powder sample No. 8
The online version of the original article can be found under doi:10.1007/s10086-014-1442-y.

O. A. Hamed $(\bowtie) \cdot$ S. Jodeh · N. Al-Hajj · A. Abo-Obeid ·

Y. Fouad

Department of Chemistry, An-Najah National University,

Nablus, West Bank, Palestine

e-mail: ohamed@najah.edu

E. M. Hamed

Hashemite University, Zarqa, Jordan 